Article

\title{
Antioxidant Activities and Chemical Constituents of Flavonoids from the Flower of Paeonia ostii
}

\author{
Huifang Zhang ${ }^{\dagger}$, Xiaofang $\mathrm{Li}^{\dagger}{ }^{\dagger}$, Ke Wu, Mengke Wang, Pu Liu * , Xinsheng Wang \\ and Ruixue Deng * \\ Chemical Engineering \& Pharmaceutical College, Henan University of Science and Technology, Luoyang 471023, \\ Henan, China; huifangz@163.com (H.Z.); xiaofl@163.com (X.L.); kewu@126.com (K.W.); \\ mengkw@163.com (M.W.); xswang@126.com (X.W.) \\ * Correspondence: liuputju@163.com (P.L.); dengliu20022002@163.com (R.D.); Tel.: +86-379-6423-1914 (P.L.) \\ + These authors contributed equally to this work.
}

Academic Editors: Arturo San Feliciano and Celestino Santos-Buelga

Received: 10 September 2016; Accepted: 16 December 2016; Published: 23 December 2016

\begin{abstract}
Paeonia ostii is a traditional medicinal plant popularly used in China. This study intended to evaluate the antioxidant properties and the chemical components of the flavonoid-rich extracts from the flowers of $P$. ostii. The results showed that the flavonoid-rich extracts from the flowers of $P$. ostii had strong scavenging capacities on 2,2'-Azinobis-(3-ethylbenzthiazoline-6-sulphonate) (ABTS), hydroxyls, superoxide anions, and 1,1-diphenyl-2-picrylhydrazyl (DPPH) radicals in a dose-dependent manner. Five flavonoids, dihydrokaempferol (1), apigenin-7-O- $\beta$-D-glucoside (2), apigenin-7-O- $\beta$-D-neohesperidoside (3), kaempferol-7-O- $\beta$-D-glucopyranoside (4), and kaempferol3-O- $\beta$-D-glucopyranosyl-7-O- $\beta$-D-glucopyranoside (5), were isolated from the flavonoid-rich extracts of the flowers of $P$. ostii. High-performance liquid chromatography (HPLC) analysis revealed that compounds 3 and 4 were abundant in the P. ostii flower and in flavonoid-rich extracts. The main components of the flower of $P$. ostii are flavonoids. The high antioxidant activity of the flavonoid-rich extracts may be attributed to the high content of flavonoids. The five isolated flavonoids were the primary antioxidant ingredients, and may play important roles in the strong antioxidant activities of this flower. Based on the obtained results, the flower of $P$. ostii could be a potential source of natural antioxidants in food and pharmaceutical applications.
\end{abstract}

Keywords: flavonoids of peony flower; Paeonia ostii; natural antioxidant; chemical constituents

\section{Introduction}

Flavonoids, which are widely distributed in plants, are naturally occurring phenolic compounds that possess many biological activities [1]. Flavonoids are also one of the most important bioactive ingredients of vegetables and fruits, and the intake of flavonoids can range between 50 and $800 \mathrm{mg} \cdot \mathrm{d}^{-1}$ in a standard human diet [2-4]. Biological activities, such as the antiallergenic, antiviral, and anti-inflammatory activities of flavonoids, may originate from their antioxidant properties [1]. Thus, flavonoid antioxidants may perhaps have a great contribution to the prevention and treatment of many diseases.

Free radicals can damage the body by starting a chain reaction in important cellular compounds, such as DNA or cell membranes. Thus, free radicals are implicated in numerous pathological conditions, such as inflammation, metabolic disorders, cellular aging, reperfusion damage, and carcinogenesis [5-7]. Additionally, antioxidants can form a defense system in order to prevent free radicals from damaging the body. Many flavonoids are excellent free radical scavengers due to their strong abilities as hydrogen or electron donors [8,9]. Therefore, most studies have been carried out in order to find new sources of natural antioxidants from flavonoids because of their activities to scavenge free radicals $[10,11]$. 
The tree peony, commonly called the "King of Flowers" in China, belongs to the Paeoniaceae family, the Paeonia genus, and is a very popular, traditional Chinese ornamental plant due to its magnificent and colorful flowers [12]. The tree peony has a history of more than 1500 years of cultivation, which has led to various flower colorations and its wide distribution in China [13].

Paeonia ostii (Paeoniaceae), one of the several wild species of Chinese tree peony, is a woody shrub that is widely distributed in China [12]. The flower of Paeonia ostii was authorized as a new food resource by the National Health and Family Planning Commission of the People's Republic of China in November 2013. Investigations into the chemical constituents of the pigment of the flowers have resulted in the identification of flavonoids [14]. Flavonoids are widely distributed in the Paeonia genus, and more than 40 flavonoids have been isolated from Paeonia. These compounds were mainly isolated from the flowers, petals, leaves, pollen, roots, and stamen of the plants $[15,16]$. Some flavonols were isolated from the flowers of P. suffruticosa, P. lactiflora, P. potaninii, P. delavayi, and P. rochii [17-19], anthocyanins were obtained from the flowers of P. decra, P. lactiflora, P. tenuifolia, P. obovata, P. japonica, P. poeaninii, P. rockii, and P. decora [18-22], and chalcones from the flowers of P. suffruticosa, P. lutea, P. delavayi, and P. trollioides [23,24]. Determination and analysis studies of nutritional ingredients showed that the seeds of $P$. ostii had abundant unsaturated fatty acids and monoterpene glycosides $[25,26]$. Moreover, studies that reported on the seeds of $P$. rockii resulted in the isolation of polyphenols with high activities in scavenging free radicals [27]. As they are a promising source of natural products, the petals of tree peony are used in aromatherapy and are also used as source of food and drink, such as in peony scented tea, peony flower drinks, peony flower sauce, and so on [28]. In addition, in traditional Chinese medicine, the tree peony flower is used in the treatment of gynecological diseases.

In the course of our studies on the bioactive constituents of tree peony flowers, we found that the ethanolic extracts of the flowers of $P$. ostii showed strong radical scavenging activities. In addition, further chemical constituents research showed that the flavonoids play important roles in radical scavenging activities. In this paper, we describe the enrichment of the total flavonoids, the radical scavenging activities of the flavonoid-rich extracts, the isolation and structure elucidation of the flavonoids isolated from the flavonoid-rich extracts, as well as the inhibitory effects of the isolated flavonoids on ABTS (2,2'-Azinobis-(3-ethylbenzthiazoline-6-sulphonate)), $\mathrm{O}^{2}{ }^{2-}$, DPPH (1,1-diphenyl-2-picrylhydrazyl), and $\bullet \mathrm{OH}$ radicals. Additionally, the HPLC (High Performance Liquid Chromatography) content of the isolated flavonoids in dried flower and in flavonoid-rich extracts were also investigated.

The aim of the current investigation was to evaluate the flavonoid composition, antioxidant activities, and the content determination of the main isolated flavonoids of the flower of P. ostii. Hopefully, this study will provide sufficient experimental evidence for good antioxidant activity and the potential for further development and utilization of flavonoids from the flower of P. ostii.

\section{Results and Discussion}

\subsection{Sample Extraction and Preparation}

Total flavonoids of the flowers of $P$. ostii were extracted and enriched in this study. The fresh flower of P. ostii was powered and extracted with ethanol at room temperature for $48 \mathrm{~h}$. The weight of the crude extract of this flower was $93.5 \mathrm{~g}$. The extract $(90 \mathrm{~g})$ was suspended in $4 \mathrm{~L}$ of distilled water, and was then loaded onto a polyamide resin column for the enrichment of total flavonoids. Polyamide resin is a polyamide powder with a large specific area and a considerable particle size processed from polyamide chip [29]. Based on the affinity of the hydrogen bonding interactions [30], polyamide resin has attracted much attention due to its high adsorption and desorption capacities, and can be used to enrich flavonoids [29,31].

The total flavonoids of different ethanol concentration elution fractions were examined and shown in Table 1. The total flavonoid content was expressed as $\mathrm{mg}$ rutin equivalents per gram dry weight of 
each extract (mg.RE. $\left.\mathrm{g}^{-1} \mathrm{DW}\right)$, and the content of all samples tested in this study ranged from 43.4 to $276.0 \mathrm{mg}$ rutin equivalent $(\mathrm{RE}) \cdot \mathrm{g}^{-1}$ dry weight. The result indicated that $50 \%$ and $60 \%$ ethanol elution have higher flavonoid contents than any other fractions. Through the enrichment of polyamide resin, the content of flavonoids of the fraction markedly increased [29,31]. Thus, the antioxidant activities and the chemical composition of these two fractions were studied further.

Table 1. Weight and flavonoid contents of different ethanol concentration elution fractions.

\begin{tabular}{|c|c|c|}
\hline Ethanol Concentration (\%) & Weight (g) & Flavonoids Content $\left(\mathrm{mg} \cdot \mathrm{g}^{-1}\right)$ \\
\hline 20 & 0.83 & $43.4 \pm 5.21$ \\
\hline 30 & 1.25 & $81.4 \pm 3.26$ \\
\hline 40 & 2.21 & $108.5 \pm 7.14$ \\
\hline 50 & 10.24 & $276.0 \pm 6.58$ \\
\hline 60 & 7.62 & $257.8 \pm 10.23$ \\
\hline 70 & 4.22 & $124.5 \pm 8.56$ \\
\hline 80 & 2.67 & $61.4 \pm 3.12$ \\
\hline 90 & 0.48 & $47.8 \pm 2.89$ \\
\hline
\end{tabular}

\subsection{Antioxidant Activity}

\subsubsection{ABTS Radical Scavenging Activity}

The ABTS free radical scavenging activity of different ethanol concentration elution fractions were examined and are shown in Figure 1. Total antioxidant activity of different ethanol concentration elution fractions of the flower of $P$. ostii were assessed by measuring the reduction of the ABTS radical as a percentage of the inhibition at $734 \mathrm{~nm}$. The extracts of different ethanol concentration elution fractions of the flower showed different inhibitory effects on ABTS free radicals. In addition, the scavenging effect of different ethanol concentration elution fractions on ABTS decreased in the order of: $60 \%$ ethanol elution fraction $>50 \%$ ethanol elution fraction $>70 \%$ ethanol elution fraction $>40 \%$ ethanol elution fraction $>30 \%$ ethanol elution fraction $>80 \%$ ethanol elution fraction $>90 \%$ ethanol elution fraction $>20 \%$ ethanol elution fraction, which were $70.47 \%, 64.82 \%, 43.15 \%, 40.78 \%, 32.54 \%, 21.78 \%$, $19.32 \%$, and $16.35 \%$, respectively, at a $40 \mu \mathrm{g} \cdot \mathrm{mL}^{-1}$ concentration. On the other hand, the results of the above-mentioned experiments indicated that, among the eight fractions, $50 \%$ and $60 \%$ ethanol elutions contained the highest flavonoid contents of all fractions. High correlations between the content of flavonoids in fractions (Table 1) and the results of antioxidant tests (Figure 1) might be indicative of the possible, high antiradical activity of the flavonoids. Flavonoids, perhaps, contribute greatly to the antioxidant activity of the flower of P. ostii. ABTS is generally used for testing the preliminary radical scavenging activity of antioxidant compounds or plant extracts, and can truly reflect the antioxidant contents in a variety of foods [32]. Flavonoids are widely distributed in genus Paeonia, and the methanolic extracts from the roots of P. suffruticosa contain the most flavonoids, which may explain its high free radical scavenging activity [33]. Moreover, the antioxidant activities of flavonoid content may partly be associated with their abilities to scavenge free radicals, and the higher the flavonoid content, and the stronger the radical scavenging activity [33].

The $50 \%$ and $60 \%$ fractions were combined into one fraction $(17.86 \mathrm{~g})$, and were considered to be the flavonoid-rich extract of $P$. ostii, which was then used for the further antioxidant assays and chemical composition isolation and analysis.

The antioxidant activity of flavonoid-rich extract from the flower of $P$. ostii was assessed by measuring the reduction of the ABTS radical as a percentage of the inhibition at $734 \mathrm{~nm}$. The ABTS scavenging activities of various concentrations of total flavonoids, from 5 to $60 \mu \mathrm{g} \cdot \mathrm{mL}^{-1}$, on ABTS radicals were shown in Figure 2a. The inhibition was found to be concentration dependent, as the scavenging capability increased with sample concentration. Vitamin $\mathrm{C}(\mathrm{Vc})$ exhibited a high radical scavenging rate when the concentrations were over $20 \mu \mathrm{g} \cdot \mathrm{mL}^{-1}$. 


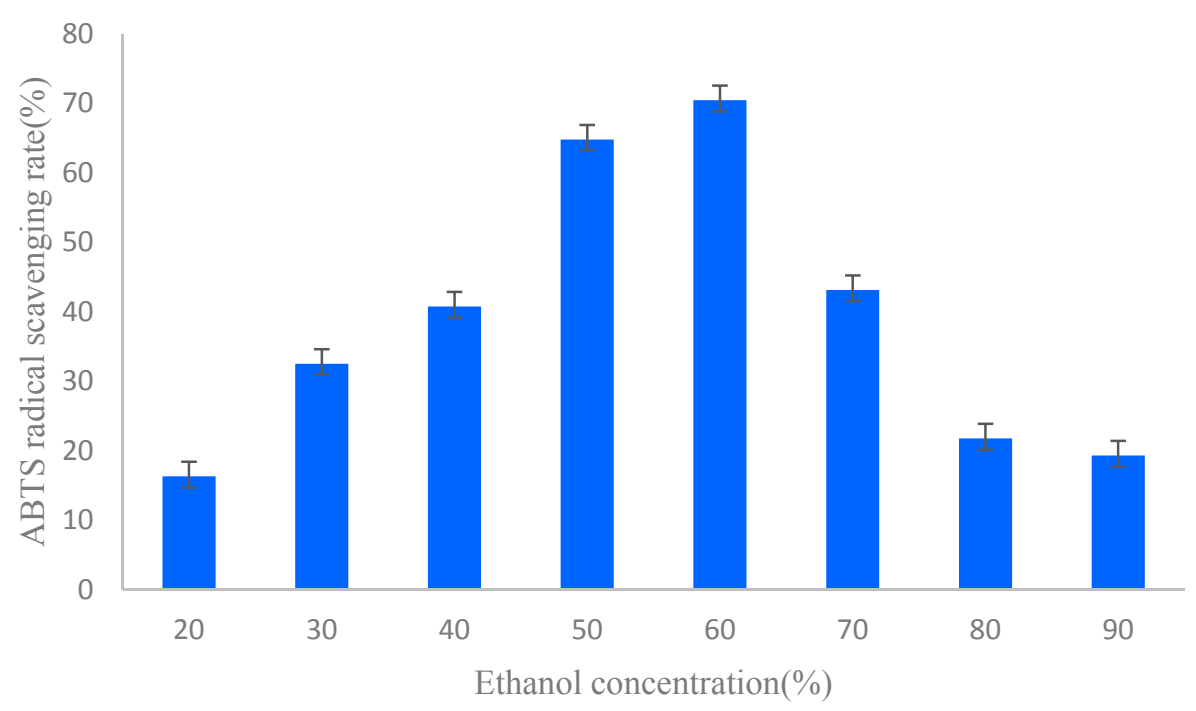

Figure 1. ABTS free radical scavenging rates of different ethanol concentration elution fractions.

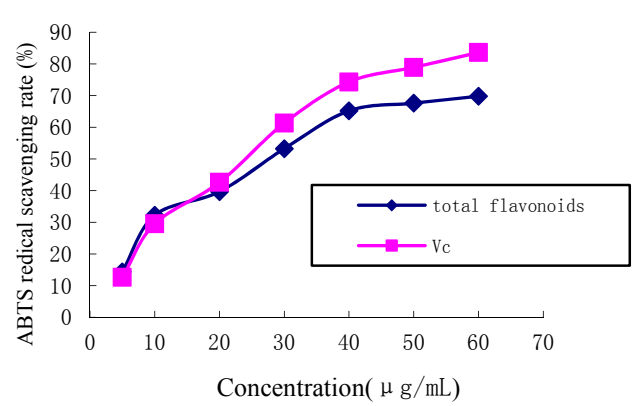

(a)

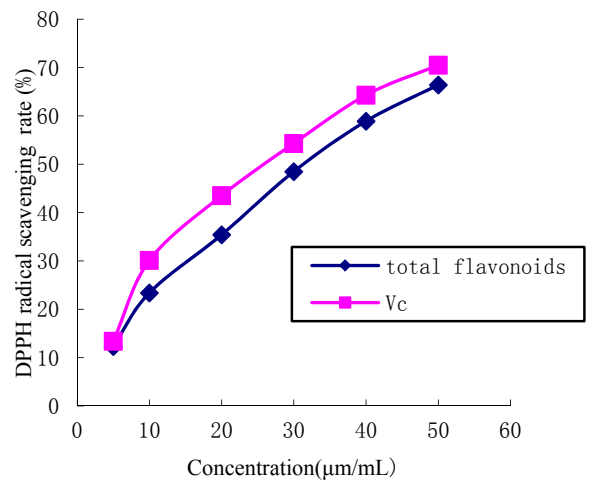

(c)

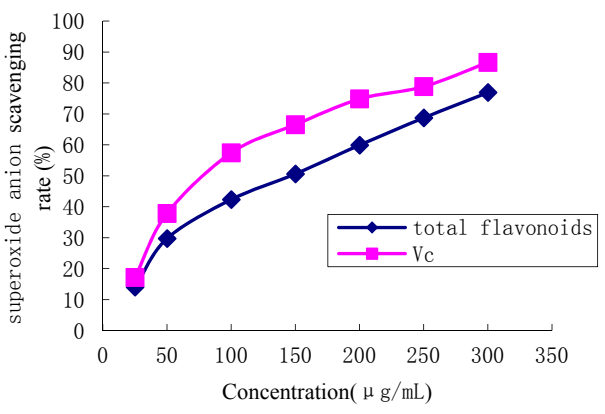

(b)

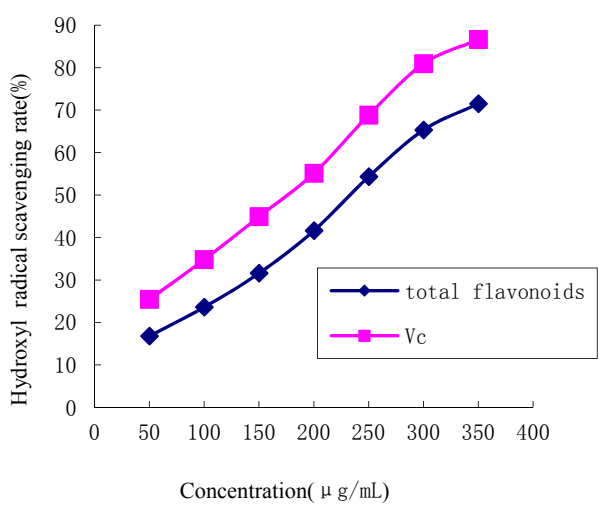

(d)

Figure 2. Effects of total flavonoids on radical scavenging rates: (a) Curve of ABTS scavenging rate; (b) curve of superoxide anion scavenging rate; (c) curve of DPPH radical scavenging rate; (d) curve of - $\mathrm{OH}$ scavenging rate.

\subsubsection{Superoxide Anion Free Radical Scavenging Activity}

Figure $2 \mathrm{~b}$ shows the inhibitory effect of the flavonoid-rich extracts from the flower of $P$. ostii on superoxide radical generation. Experiments were performed under controlled conditions. The results indicated that, in the range of $50-350 \mu \mathrm{g} \cdot \mathrm{mL}^{-1}$, the flavonoid-rich extracts from the flower of P. ostii interfered with superoxide anion free radicals in a dose-dependent manner. The $\mathrm{IC}_{50}$ values of 
flavonoid-rich extracts and Vc were $131.12 \pm 4.56 \mu \mathrm{g} \cdot \mathrm{mL}^{-1}$ and $72.34 \pm 2.56 \mu \mathrm{g} \cdot \mathrm{mL}^{-1}$, respectively. More than 1.8 times the concentration of flavonoid-rich extracts was needed to have an effect on superoxide anion free radicals relative to $\mathrm{Vc}_{\mathrm{c}}$ in this study. There were reports on the superoxide anion free radicals of the flower of $P$. ostii. The $\mathrm{IC}_{50}$ value of methanol extract from the flowers of P. suffruticosa on the superoxide anion free radical was $199.0 \mu \mathrm{g} \cdot \mathrm{mL}^{-1}$ [34], which was higher than that of the purified flavonoid-rich extract obtained in this study.

\subsubsection{DPPH Radical Scavenging Activity}

Various methods have been designed to measure antioxidant power. The reaction of the colored DPPH radical is a popular method to evaluate the strength of antioxidants. Figure $2 \mathrm{c}$ shows the radical scavenging ability of flavonoid-rich extracts on DPPH. At concentrations from 5.0 to $50.0 \mu \mathrm{g} \cdot \mathrm{mL}^{-1}$, the DPPH radical scavenging ability of flavonoid-rich extracts ranged from $13.4 \%$ to $68.6 \%$, while that of Vc was $15.7 \%-72.8 \%$. IC 50 values were $32.6 \pm 0.54 \mu \mathrm{g} \cdot \mathrm{mL}^{-1}$ and $26.4 \pm 0.61 \mu \mathrm{g} \cdot \mathrm{mL}^{-1}$ for flavonoid-rich extracts and $\mathrm{Vc}$, respectively. The flavonoid-rich extracts had a strong scavenging activity on DPPH radicals, based on the fact that the effective concentration to inhibit radical scavenging ability was slightly higher than that of pure Vc. The free radical scavenging activity of extracts from the flower of genus Paeonia has been demonstrated in several studies. The free radical scavenging activity of extracts from the flower of genus Paeonia has been demonstrated in several studies. The antioxidant activity of the extracts from the flowers of the Zhongyuan tree penoy cultivars varied from 7.66 to $31.36 \mathrm{mg} \mathrm{Vc}$ equivalents. $\mathrm{g}^{-1}$ for the DPPH assay, and for P. ostii (Feng dan bai) was $8.63 \mathrm{mg}$ Vc equivalents. $\mathrm{g}^{-1}$ for DPPH [33]. The scavenging activity of crude extract from the flower of P. suffruticosa on DPPH radical was $4.77 \%$ of maximum inhibition at $20 \mu \mathrm{g} \cdot \mathrm{mL}^{-1}$ concentration [35]. Therefore, the purified flavonoid-rich extract obtained in this study was superior to most of the other reported values.

The DPPH radical assay is based on the reduction of alcoholic DPPH solution in the presence of a hydrogen donating antioxidant [36]. The 2,2-diphenyl-1-picrylhydrazyl radical (DPPH•) can be reduced to its hydrazine form (DPPH-H) by antioxidants because of their hydrogen-donating abilities [37]. Like many other polyphenols, flavonoids are excellent free radical scavengers because they are highly reactive as hydrogen or electron donors $[8,9]$. Thus, commercially available DPPH• is becoming widely used to investigate the free radical scavenging activities of flavonoid-rich extracts and flavonoids.

\subsubsection{Hydroxyl Radical Scavenging Activity}

As an extremely active free radical in biological systems, the hydroxyl radical can cause oxidative damage to biological macromolecules, including lipids, proteins, and nucleic acids [38]. Antioxidants can prevent damage to the hydroxyl radical of biological macromolecules. Additionally, the scavenging capacity on hydroxyl radicals is directly related to the antioxidant capability [39]. The radical scavenging results of flavonoid-rich extracts on hydroxyl radicals are shown in Figure 2d. The hydroxyl radical scavenging activity of flavonoid-rich extracts and $V_{c}$ both increased with an increase in concentrations, and the scavenging activity at $200 \mu \mathrm{g} \cdot \mathrm{mL}^{-1}$, for flavonoid-rich extracts and Vc, were $42.5 \%$ and $57.1 \%$, respectively. In addition, Vc showed an excellent scavenging activity with an $\mathrm{IC}_{50}$ value of $162.12 \pm 3.15 \mu \mathrm{g} \cdot \mathrm{mL}^{-1}$, and flavonoid-rich extracts were also observed to have scavenging activity with an $\mathrm{IC}_{50}$ value of $233.54 \pm 6.47 \mu \mathrm{g} \cdot \mathrm{mL}^{-1}$, which was higher than that of methanol extract from the flowers of $P$. suffruticosa with the $\mathrm{IC}_{50}$ value $193.18 \mu \mathrm{g} \cdot \mathrm{mL}^{-1}$ [35]. Flavonoid-rich extracts remarkably inhibited hydroxyl radicals.

\subsection{Structural Elucidation of the Isolated Compounds}

The chemical structures of the isolated compounds were identified according to their ESI-MS (Electrospray Ionization Mass Spectrometry), ${ }^{1} \mathrm{H}-\mathrm{NMR}$ (Proton Nuclear Magnetic Resonance) and ${ }^{13}$ C-NMR (Carbon Nuclear Magnetic Resonance) data. The chemical structures of the isolated compounds are shown in Figure 3. The data of each compound are given as follows: 
Dihydrokaempferol (1), light yellow crystallized powder. Additionally, it has a strong ultraviolet absorption under UV254. ESI-MS m/z: $287[\mathrm{M}-\mathrm{H}]^{-}\left(\mathrm{C}_{15} \mathrm{H}_{12} \mathrm{O}_{6}\right) \cdot{ }^{1} \mathrm{H}-\mathrm{NMR}\left(400 \mathrm{MHz}, \mathrm{CD}_{3} \mathrm{OD}\right) \delta$ : $4.54(1 \mathrm{H}, \mathrm{d}, J=11.6 \mathrm{~Hz}, \mathrm{H}-3), 4.97(1 \mathrm{H}, \mathrm{d}, J=11.6 \mathrm{~Hz}, \mathrm{H}-2), 5.87(1 \mathrm{H}, \mathrm{d}, J=1.59 \mathrm{~Hz}, \mathrm{H}-6), 5.91(1 \mathrm{H}$, $\mathrm{d}, J=1.59 \mathrm{~Hz}, \mathrm{H}-8), 7.35\left(2 \mathrm{H}, \mathrm{d}, J=8.56 \mathrm{~Hz}, \mathrm{H}-2^{\prime}, 6^{\prime}\right), 6.82\left(2 \mathrm{H}, \mathrm{d}, J=8.56 \mathrm{~Hz}, \mathrm{H}-3^{\prime}, 5^{\prime}\right) .{ }^{13} \mathrm{C}-\mathrm{NMR}$ $\left(100 \mathrm{~Hz}, \mathrm{CD}_{3} \mathrm{OD}\right)$ 8: 84.99 (C-2), 73.65 (C-3), 198.53 (C-4), 165.34 (C-5), 97.32 (C-6), 168.76 (C-7), 96.28 (C-8), 164.57 (C-9), 101.85 (C-10), $129.30\left(\mathrm{C}-1^{\prime}\right), 130.38\left(\mathrm{C}-2^{\prime}\right), 116.14\left(\mathrm{C}-3^{\prime}\right), 159.25\left(\mathrm{C}-4^{\prime}\right), 116.14\left(\mathrm{C}-5^{\prime}\right)$, $130.38\left(\mathrm{C}-6^{\prime}\right)$. Based on the above-mentioned data and a comparison with data from the literature [40], compound 1 was identified as dihydrokaempferol.

Apigenin-7-O- $\beta$-D-glucoside (2) was obtained as light yellow crystallized powder, and showed strong ultraviolet absorption under UV254. ESI-MS $m / z: 434[\mathrm{M}-\mathrm{H}]^{-}\left(\mathrm{C}_{21} \mathrm{H}_{21} \mathrm{O}_{10}\right) .{ }^{1} \mathrm{H}-\mathrm{NMR}(400 \mathrm{MHz}$, DMSO) $\delta: 6.88(1 \mathrm{H}, \mathrm{s}, \mathrm{H}-3), 6.45(1 \mathrm{H}, \mathrm{d}, J=1.59 \mathrm{~Hz}, \mathrm{H}-6), 6.83(1 \mathrm{H}, \mathrm{d}, J=1.59 \mathrm{~Hz}, \mathrm{H}-8), 7.96(2 \mathrm{H}, \mathrm{d}$, $\left.J=8.8 \mathrm{~Hz}, \mathrm{H}-2^{\prime}, 6^{\prime}\right), 6.97\left(2 \mathrm{H}, \mathrm{d}, J=8.8 \mathrm{~Hz}, \mathrm{H}-3^{\prime}, 5^{\prime}\right) .{ }^{13} \mathrm{C}-\mathrm{NMR}\left(100 \mathrm{MHz}, \mathrm{CD}_{3} \mathrm{OD}\right) \delta: 164.23(\mathrm{C}-2)$, 103.07 (C-3), 181.97 (C-4), 156.91 (C-5), 94.81 (C-6), 162.92 (C-7), 99.48 (C-8), 161.35 (C-9), 105.30 (C-10), $120.98\left(\mathrm{C}-1^{\prime}\right), 128.59\left(\mathrm{C}-2^{\prime}\right), 115.97\left(\mathrm{C}-3^{\prime}\right), 161.08\left(\mathrm{C}-4^{\prime}\right), 115.97\left(\mathrm{C}-5^{\prime}\right), 128.59\left(\mathrm{C}-6^{\prime}\right), 99.86\left(\mathrm{C}-1^{\prime \prime}\right), 73.07$ $\left(\mathrm{C}-2^{\prime \prime}\right), 76.40\left(\mathrm{C}-3^{\prime \prime}\right), 69.52\left(\mathrm{C}-4^{\prime \prime}\right), 77.14\left(\mathrm{C}-5^{\prime \prime}\right)$. Based on the data, and a comparison with data from the literature [41], compound 2 was identified as apigenin-7-O- $\beta$-D-glucoside.

Apigenin-7-O- $\beta$-D-neohesperidoside (3) was obtained as an amorphous yellow powder, and exhibited strong ultraviolet absorption under UV254. ESI-MS $m / z: 577[\mathrm{M}-\mathrm{H}]^{-}\left(\mathrm{C}_{27} \mathrm{H}_{30} \mathrm{O}_{14}\right) .{ }^{1} \mathrm{H}-\mathrm{NMR}$ $\left(400 \mathrm{MHz}, \mathrm{CD}_{3} \mathrm{OD}\right) \delta: 6.60(1 \mathrm{H}, \mathrm{s}, \mathrm{H}-3), 6.40(1 \mathrm{H}, \mathrm{d}, J=1.8 \mathrm{~Hz}, \mathrm{H}-6), 6.71(1 \mathrm{H}, \mathrm{d}, J=1.8 \mathrm{~Hz}, \mathrm{H}-8), 7.82$ $\left(2 \mathrm{H}, \mathrm{d}, J=8.2 \mathrm{~Hz}, \mathrm{H}-2^{\prime}, 6^{\prime}\right), 6.89\left(2 \mathrm{H}, \mathrm{d}, J=8.2 \mathrm{~Hz}, \mathrm{H}-3^{\prime}, 5^{\prime}\right) .{ }^{13} \mathrm{C}-\mathrm{NMR}\left(100 \mathrm{MHz}, \mathrm{CD}_{3} \mathrm{OD}\right) \delta: 166.67$ (C-2), 104.12 (C-3), 183.97 (C-4), 162.93 (C-5), 100.97 (C-6), 164.34 (C-7), 95.90 (C-8), 158.90 (C-9), 107.01 (C-10), $122.96\left(\mathrm{C}-1^{\prime}\right), 129.67\left(\mathrm{C}-2^{\prime}\right), 117.04\left(\mathrm{C}-3^{\prime}\right), 162.88\left(\mathrm{C}-4^{\prime}\right), 117.04\left(\mathrm{C}-5^{\prime}\right), 129.63\left(\mathrm{C}-6^{\prime}\right), 99.75\left(\mathrm{C}-1^{\prime \prime}\right)$, $79.03\left(\mathrm{C}-2^{\prime \prime}\right), 79.03\left(\mathrm{C}-3^{\prime \prime}\right), 71.40\left(\mathrm{C}-4^{\prime \prime}\right), 78.30\left(\mathrm{C}-5^{\prime \prime}\right), 62.45\left(\mathrm{C}-6^{\prime \prime}\right), 102.54\left(\mathrm{C}-1^{\prime \prime \prime}\right), 72.22\left(\mathrm{C}-2^{\prime \prime \prime}\right), 72.22$ $\left(\mathrm{C}-3^{\prime \prime \prime}\right), 73.99\left(\mathrm{C}-4^{\prime \prime \prime}\right), 70.01\left(\mathrm{C}-5^{\prime \prime \prime}\right), 18.29\left(\mathrm{C}-6^{\prime \prime \prime}\right)$. Based on the data, and a comparison with data from the literature [42], compound 3 was identified as apigenin-7-O- $\beta$-D-neohesperidoside.

Kaempferol-7-O- $\beta$-D-glucopyranoside (4) was obtained as an amorphous yellowish powder, and presented strong ultraviolet absorption under UV254. ESI-MS m/z: $447[\mathrm{M}-\mathrm{H}]^{-}\left(\mathrm{C}_{21} \mathrm{H}_{20} \mathrm{O}_{11}\right) .{ }^{1} \mathrm{H}-\mathrm{NMR}$ (400 MHz, DMSO) $\delta: 6.79(1 \mathrm{H}, \mathrm{d}, J=2.2 \mathrm{~Hz}, \mathrm{H}-8), 6.44(1 \mathrm{H}, \mathrm{d}, J=2.2 \mathrm{~Hz}, \mathrm{H}-6), 8.06(2 \mathrm{H}, \mathrm{d}, J=8.9 \mathrm{~Hz}$, $\left.\mathrm{H}-2^{\prime}, 6^{\prime}\right), 6.89\left(2 \mathrm{H}, \mathrm{d}, J=8.9 \mathrm{~Hz}, \mathrm{H}-3^{\prime}, 5^{\prime}\right) .{ }^{13} \mathrm{C}-\mathrm{NMR}(100 \mathrm{~Hz}, \mathrm{DMSO}) \delta: 147.3$ (C-2), 135.9 (C-3), 175.9 (C-4), 1620.1 (C-5), 98.7 (C-6), 162.5 (C-7), 94.3 (C-8), 155.6 (C-9), 104.6 (C-10), 121.4 (C-1'), 129.5 (C-2', $\left.6^{\prime}\right), 78.0\left(\mathrm{C}-3^{\prime}, 5^{\prime}\right), 159.2\left(\mathrm{C}-4^{\prime}\right)$. Based on the data, and a comparison with data from the literature [43], compound 4 was identified as kaempferol-7-O- $\beta$-D-glucopyranoside.

Kaempferol-3-O- $\beta$-D-glucopyranosyl-7-O- $\beta$-D-glucopyranoside (5) was obtained as an amorphous yellowish powder, and has strong ultraviolet absorption under UV254. ESI-MS $m / z: 609[\mathrm{M}-\mathrm{H}]^{-}\left(\mathrm{C}_{27} \mathrm{H}_{30} \mathrm{O}_{16}\right)$. ${ }^{1} \mathrm{H}-\mathrm{NMR}\left(400 \mathrm{MHz}, \mathrm{CD}_{3} \mathrm{OD}\right) \delta: 6.445(1 \mathrm{H}, \mathrm{d}, J=2.1 \mathrm{~Hz}, \mathrm{H}-6), 6.791(1 \mathrm{H}, \mathrm{d}, J=2.1 \mathrm{~Hz}, \mathrm{H}-8)$, $8.07\left(2 \mathrm{H}, \mathrm{d}, J=8.9 \mathrm{~Hz}, \mathrm{H}-2^{\prime}, 6^{\prime}\right), 6.90\left(2 \mathrm{H}, \mathrm{d}, J=8.9 \mathrm{~Hz}, \mathrm{H}-3^{\prime}, 5^{\prime}\right) .{ }^{13} \mathrm{C}-\mathrm{NMR}(100 \mathrm{MHz}$, $\left.\mathrm{CD}_{3} \mathrm{OD}\right)$ 8: 155.97 (C-2), 133.41 (C-3), 177.60 (C-4), 160.81 (C-5), 99.29 (C-6), 162.77 (C-7), 94.6 (C-8), 155.97 (C-9), 105.60 (C-10), $120.73\left(\mathrm{C}-1^{\prime}\right), 130.60\left(\mathrm{C}-2^{\prime}\right), 115.11\left(\mathrm{C}-3^{\prime}\right), 160.09\left(\mathrm{C}-4^{\prime}\right), 115.11$ $\left(\mathrm{C}-5^{\prime}\right), 130.60\left(\mathrm{C}-6^{\prime}\right), 99.64\left(\mathrm{C}-1^{\prime \prime}\right), 73.03\left(\mathrm{C}-2^{\prime \prime}\right), 76.37\left(\mathrm{C}-3^{\prime \prime}\right), 69.51\left(\mathrm{C}-4^{\prime \prime}\right), 77.12\left(\mathrm{C}-5^{\prime \prime}\right), 60.76\left(\mathrm{C}-6^{\prime \prime}\right)$, $100.63\left(\mathrm{C}-1^{\prime \prime \prime}\right), 74.17\left(\mathrm{C}-2^{\prime \prime \prime}\right), 76.63\left(\mathrm{C}-3^{\prime \prime \prime}\right), 69.85\left(\mathrm{C}-4^{\prime \prime \prime}\right), 77.52\left(\mathrm{C}-5^{\prime \prime \prime}\right), 60.57\left(\mathrm{C}-6^{\prime \prime \prime}\right)$. Based on the data, and a comparison with data from the literature [44], compound 5 was identified as kaempferol-3-O- $\beta$-D-glucopyranosyl-7-O- $\beta$-D-glucopyranoside.

Flavonoids are widely distributed in the flowers, petals, leaves, pollen, roots, and stamen of the plants of genus Paeonia $[15,16]$. Compounds $\mathbf{2}-\mathbf{5}$ were previously isolated from the flowers of genus Paeonia, kaempferol-3-O- $\beta$-D-glucopyranosyl-7-O- $\beta$-D-glucopyranoside was isolated from the petals of P. lactiflora and P. suffruticosa $[15,16,20]$, and apigenin-7-O- $\beta$-D-neohesperidoside, kaempferol-7-O- $\beta$-D-glucopyranoside, and apigenin-7-O- $\beta$-D-glucoside were obtained from the flower of P. suffruticosa $[21,22]$. 
<smiles>C=C1c2c(O)cc(O)cc2NC(c2ccc(O)cc2)C1O</smiles>

1

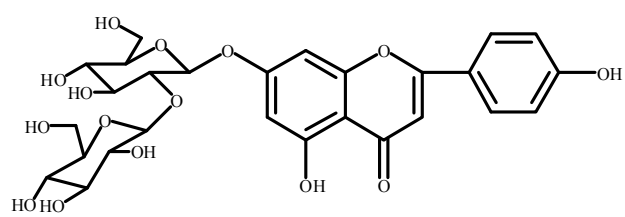

3

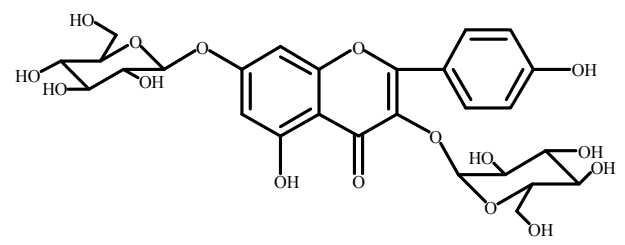

5<smiles>O=c1cc(-c2ccc(O)cc2)oc2cc(OC3CC4CC3C(O)C4CO)cc(O)c12</smiles>

2

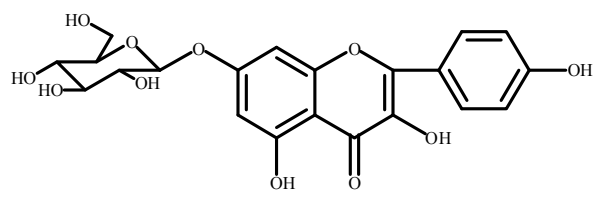

4

Figure 3. The structures of compounds: 1-5 (dihydrokaempferol (1); apigenin-7-O- $\beta$-D-glucoside (2); apigenin-7-O- $\beta$-D-neohesperidoside (3); kaempferol-7-O- $\beta$-D-glucopyranoside (4); kaempferol-3-O- $\beta$ D-glucopyranosyl-7-O- $\beta$-D-glucopyranoside (5)).

\subsection{Antioxidant Capacities of Isolated Compounds}

The activities of these five isolated compounds are shown in Table 2. The five isolated compounds showed significant radical scavenging activities against $\mathrm{ABTS}, \mathrm{O} \bullet^{2-}$, DPPH and $\bullet \mathrm{OH}$ radicals. Amongst these, compounds $\mathbf{1}$ and $\mathbf{5}$ possessed the strongest radical scavenging activities against all tested radicals, including ABTS, $\mathrm{O}^{2-}$, DPPH and $\bullet \mathrm{OH}$ radicals, with $\mathrm{EC}_{50}$ values of $25.4,75.8$, 24.6, and $141.9 \mu \mathrm{g} \cdot \mathrm{mL}^{-1}$ for 1 and 23.5, 69.4, 20.9, and 121.8 for 5 , respectively. Based on the $\mathrm{EC}_{50}$ values against $\mathrm{ABTS}$ and $\bullet \mathrm{OH}$ radicals, the activity order of the five isolated flavonoids was as follows: Compound $\mathbf{5}>$ compound $\mathbf{1}>$ compound $\mathbf{4}>$ compound $\mathbf{2}>$ compound $\mathbf{3}$. The activity of compound $\mathbf{5}$ surpassed that of the positive control drug $\left(\mathrm{Vc}_{\mathrm{c}}\right)$.

Table 2. Scavenging effects of flavonoids from P. ostii on radicals.

\begin{tabular}{ccccc}
\hline \multirow{2}{*}{ Compounds } & \multicolumn{4}{c}{$\mathrm{IC}_{\mathbf{5 0}}\left(\boldsymbol{\mu \mathrm { g } \cdot \mathbf { m L } ^ { - \mathbf { 1 } } )}\right.$} \\
\cline { 2 - 5 } & ABTS & $\mathbf{O \bullet}^{\mathbf{2}-}$ & $\mathbf{D P P H \bullet}$ & $\bullet \mathbf{O H}$ \\
\hline $\mathbf{1}$ & $25.4 \pm 0.68$ & $75.8 \pm 0.11$ & $24.6 \pm 0.41$ & $141.9 \pm 0.17$ \\
$\mathbf{2}$ & $36.5 \pm 0.76$ & $86.4 \pm 0.21$ & $34.2 \pm 0.98$ & $155.2 \pm 0.25$ \\
$\mathbf{3}$ & $41.1 \pm 0.24$ & $84.2 \pm 0.09$ & $40.1 \pm 0.13$ & $157.3 \pm 0.17$ \\
$\mathbf{4}$ & $35.7 \pm 0.35$ & $80.1 \pm 0.14$ & $35.3 \pm 0.21$ & $134.8 \pm 0.12$ \\
$\mathbf{5}$ & $23.5 \pm 0.44$ & $69.4 \pm 0.17$ & $20.9 \pm 0.27$ & $121.8 \pm 0.14$ \\
$\mathbf{V c}$ & $28.7 \pm 2.54$ & $72.3 \pm 2.56$ & $26.4 \pm 0.21$ & $132.1 \pm 3.15$ \\
\hline
\end{tabular}

\subsection{HPLC Analysis}

The flavonoid-rich extracts and the isolated flavonoids showed significant radical scavenging activity. In order to further understand the relationship between the content of isolated flavonoids in the flavonoid-rich extracts and the radical scavenging activities of the total flavonoids, the content of the isolated flavonoids in the dried flower and flavonoid-rich extracts of $P$. ostii were analyzed. Five isolated flavonoids, dihydrokaempferol (1), apigenin-7-O- $\beta$-D-glucoside (2), 
apigenin-7-O- $\beta$-D-neohesperidoside (3), kaempferol-7-O- $\beta$-D-glucopyranoside (4), and kaempferol3-O- $\beta$-D-glucopyranosyl-7-O- $\beta$-D-glucopyranoside (5), were quantified.

The representative chromatograms of the standard mixture solution and flavonoid-rich extracts are depicted in Figure 4. The HPLC method provided repeatable and good separations for the five isolated flavonoid compounds. Based on the chromatograms, dihydrokaempferol (1), apigenin-7-O$\beta$-D-glucoside (2), apigenin-7-O- $\beta$-D-neohesperidoside(3), kaempferol-7-O- $\beta$-D-glucopyranoside (4), and kaempferol-3-O- $\beta$-D-glucopyranosyl-7-O- $\beta$-D-glucopyranoside (5) were well separated at a retention time of $3.78 \mathrm{~min}, 5.0 \mathrm{~min}, 5.69 \mathrm{~min}, 7.74 \mathrm{~min}$, and $10.42 \mathrm{~min}$, respectively. In addition, the contents of individual flavonoids identified in the P. ostii flower, and in flavonoid-rich extracts, are presented in Table 3. According to the HPLC results, compounds 3 and 4 were abundant in P. ostii flower and in flavonoid-rich extracts (the contents of compounds 3 and 4 were $10.25 \pm 0.35$ and $6.44 \pm 0.45 \mathrm{mg} \cdot \mathrm{g}^{-1}$ of dry sample, respectively). Compounds 1-5 perhaps contribute greatly to the strong antioxidant activity of this flower. The high antioxidant activity of the extracts may be attributed to their high content of flavonoids.

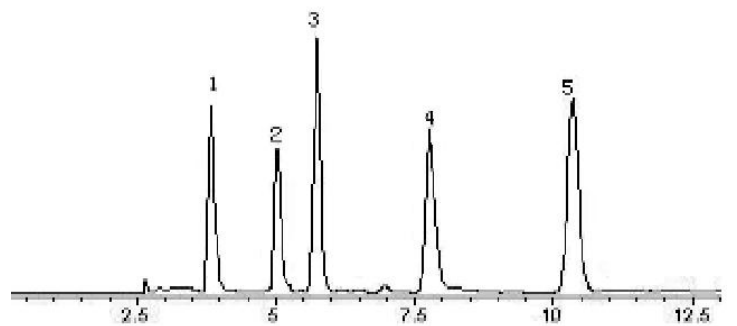

(a)

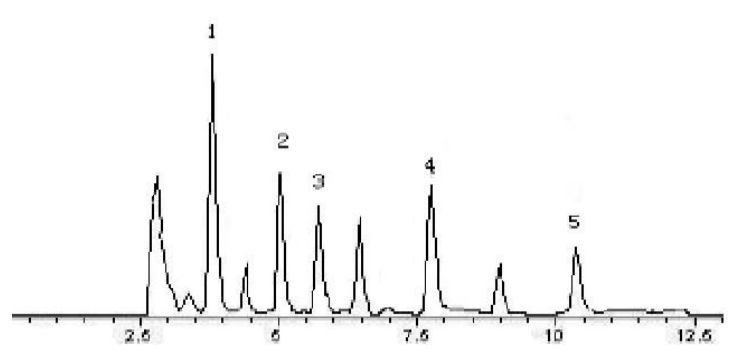

(b)

Figure 4. Chromatograms of chemical reference substances (a) and sample (b) in $360 \mathrm{~nm}$ (1-Apigenin-7$O$ - $\beta$-D-neohesperidoside (3); 2 -kaempferol-3-O- $\beta$-D-glucopyranosyl-7-O- $\beta$-D-glucopyranoside (4); 3 -kaempferol-7-O- $\beta$-D-glucopyranoside (5) 4-apigenin-7-O- $\beta$-D-glucopyranoside (2); 5 dihydrokaempferol (1)).

Table 3. Results of the determination of samples $\left(\mathrm{mg} \cdot \mathrm{g}^{-1}\right)$.

\begin{tabular}{cccccc}
\hline Samples & $\mathbf{1}$ & $\mathbf{2}$ & $\mathbf{3}$ & $\mathbf{4}$ & $\mathbf{5}$ \\
\hline Flavonoid-rich extracts & $32.18 \pm 1.21$ & $84.75 \pm 1.24$ & $183.42 \pm 2.74$ & $106.25 \pm 3.15$ & $66.17 \pm 2.23$ \\
Dried flower & $0.62 \pm 0.08$ & $1.66 \pm 0.34$ & $10.25 \pm 0.35$ & $6.44 \pm 0.45$ & $1.02 \pm 0.08$ \\
\hline
\end{tabular}

\section{Materials and Methods}

\subsection{Plant Material}

Fresh flowers of P. ostii, originating in Henan, China, were collected from Luoyang Tuqiao flower and seeding Co. Ltd., Luoyang, Henan, China. They were identified by teacher Zhipeng Wei (CEO of Luoyang Tuqiao flower and seeding Co., Ltd., Luoyang, Henan, China) in May 2014. A voucher specimen was deposited in the Specimens Hall of Natural Resources of Funiu Mountains, Henan University of Science and Technology.

\subsection{Reagent and Chemicals}

All chemicals used were of analytical or HPLC grade. Lecithinum, 1,1-diphenyl-2-picrylhydrazyl radical (DPPH), [2,20-azinobis-(3-ethylbenzothiazoline-6-sulfonic acid)] diammonium salt (ABTS), nicotinamide adenine dinucleotide (NADH), phenazine methyl sulfate (PMS), nitrotetrazolium blue chloride (NBT), and Vitamin C were obtained from Aladdin Industrial Corporation (Shanghai, China). 2-Hydroxybenzoic acid, disodium hydrogen phosphate dodecahydrate, sodium dihydrogen phosphate, ferrous sulfate, and hydrogen peroxide were purchased from Tianjin Kermel Chemical Reagent Co., Ltd. 
(Tianjin, China). Toypear HW-40C (Tosoh, Japan) was supplied by Beijng Greenberbs Science and Technology Development Co., Ltd. (Beijing, China). Silica gel GF254 plates and silica gel were purchased from Qingdao Marine Chemical Co. (Qingdao, China). The water was purified using a ULUP-111-10T water purification system (Chengdu, China).

\subsection{Apparatus}

All of the ${ }^{1} \mathrm{H}$ and ${ }^{13} \mathrm{C}$ nuclear magnetic resonance (NMR) spectra were recorded on a Bruker Avance 400 spectrometer (Karlsruhe, Germany), using tetramethylsilane (TMS) as an internal standard, at $400\left({ }^{1} \mathrm{H}\right)$ and $100 \mathrm{MHz}\left({ }^{13} \mathrm{C}\right)$. The chemical shifts in the NMR spectra were recorded as $\delta$ values. ESI-MS was obtained on a Waters Alliance 2695, Quattro Micro TM ESI instrument (Milford, MA, USA).

Semi-preparative HPLC was performed using a Waters 600 with Waters TP pump, UV-2487 detector (Milford, MA, USA), and a YMC-Pack ODS-A column (SH-343-5, Tokyo, Japan). Column chromatography (CC) was performed on silica gel (Qingdao Marine Chemical Co., Ltd., Qingdao, China) or Toyopearl HW-40 (Tosoh, Tokyo, Japan). Thin-layer chromatography (TLC) was performed on silica gel GF254 plates (Qingdao Marine Chemical Co., Ltd., Qingdao, China), visualization was done under $\mathrm{UV}$ light and by spraying with $\mathrm{Ce}_{2} \mathrm{SO}_{4}$ or phosphomolybdic acid hydrate, followed by heating. HPLC analysis was carried out on Agilent 1100 (Agilent, Palo Alto, CA, USA) equipped with a photo-diode-detector (DAD), quarternary Pump G1311A, an autosampler G1313A, a G1322A vacuum degasser, and the Agilent HPLC workstation. The UV absorbance was measured at $510 \mathrm{~nm}$ using an ultraviolet-visible spectrophotometer, UV-2600 (Shimadzu, Suzhou, China).

\subsection{Sample Extraction and Preparation}

The procedure of extraction of total flavonoids, as described in the literature, has been modified [45]. The fresh flower of P. ostii was collected, and the peduncle, receptacles, and calyx were removed from the large flower, leaving only the petals of the flower. The $30 \mathrm{Kg}$ petals were powered, and extracted thrice, each time with $20 \mathrm{~L}$ of ethanol at room temperature for $48 \mathrm{~h}$. The combined ethanol extract was filtered and evaporated at $60^{\circ} \mathrm{C}$ under reduced pressure using a vacuum rotary evaporator (Yuhua RE-2000A, Zhengzhou, China). The weight of the crude extract of this flower was $93.5 \mathrm{~g}$.

The crude extract $(90 \mathrm{~g})$ was suspended in distilled water and subsequently filtered using filter papers. The filtrates were loaded onto the polyamide column (inner diameter $15 \mathrm{~cm}$, length $120 \mathrm{~cm}$, $8000 \mathrm{~mL}$ ) for total flavonoid enrichment at a flow rate of $4 \mathrm{BV} / \mathrm{h}$. After the polyamide resin was saturated with flavonoid compounds, the resin column was washed with distilled water and $20 \%$, $30 \%, 40 \%, 50 \%, 60 \%, 70 \%, 80 \%$, and $90 \%$ ethanol $(v / v)$ with isocratic modes at a flow rate of $4.0 \mathrm{BV} / \mathrm{h}$. The content of total flavonoids in each desorbed fraction was analyzed by UV-2600 (Ultraviolet-visible 2600) spectrophotometer. The desorbed fractions were concentrated in an evaporator at $60^{\circ} \mathrm{C}$ under vacuum. The dried products of each fraction were weighed, and the content and recovery yields of total flavonoids were calculated.

\subsection{Determination of Total Flavonoid Content}

Using the aluminum chloride colorimetric method, the total flavonoid contents were determined, based on the literature reported, with some modifications [46]. Briefly, $4.0 \mathrm{~mL} 70 \%$ aqueous ethanol $(v / v)$ and $0.3 \mathrm{~mL} \mathrm{NaNO}_{2}(5 \%, w / v)$ were added to $1.0 \mathrm{~mL}$ of sample solution. After shaking, the mixture was incubated at room temperature for $6 \mathrm{~min}$, and then $0.3 \mathrm{~mL} \mathrm{AlCl} 3(10 \%, w / v)$ and $4.0 \mathrm{~mL} \mathrm{NaOH}(1 \mathrm{~mol} / \mathrm{L})$ were added, followed by the addition of distilled water to reach a final volume of $10.0 \mathrm{~mL}$. The solution was shaken and then allowed to stand at room temperature for $15 \mathrm{~min}$. Finally, the absorbance was measured in $1 \mathrm{~cm}$ quartz cuvettes at $510 \mathrm{~nm}$ against the control with a UV-2600 spectrophotometer (Shimadzu, Suzhou, China). The control contained all the reaction reagents, except for the test sample. A calibration curve was measured, using a standard of rutin, the regression equation was: $y=0.02018 x+0.16\left(R^{2}=0.99925\right)$ (where $y$ is the absorption and $x$ is the 
rutin concentration in $\mu \mathrm{g} \cdot \mathrm{mL}^{-1}$ ). The results of total flavonoid contents of the extracts were calculated from the calibration curve and expressed as $\mathrm{mg}$ rutin equivalents per gram dry weight of extract $\left(\mathrm{mg} \cdot \mathrm{RE} \cdot \mathrm{g}^{-1}\right)$.

\subsection{Antioxidant Activity}

\subsubsection{ABTS Radical Scavenging Activity}

ABTS radical scavenging activity was determined using the method described in the literature with slight changes [41]. A stock solution of ABTS radical cations was prepared by mixing $50 \mathrm{~mL}$ $2.0 \mathrm{mmol} \cdot \mathrm{L}^{-1} \mathrm{ABTS}$ and $200 \mathrm{~mL} 70 \mathrm{mmol} \cdot \mathrm{L}^{-1}$ potassium persulfate in an amber bottle. To produce ABTS radical cations, the mixture was incubated in the dark at room temperature and left to stand for $12-16 \mathrm{~h}$, and then was diluted with phosphate buffer $(\mathrm{pH}=7.4)$ and measured using a spectrophotometer absorbance at $735 \mathrm{~nm}$ of $0.7 \pm 0.02$. One hundred microliters of extract solution at different concentrations was added to $1.9 \mathrm{~mL}$ of ABTS reaction system. After being mixed and placed at room temperature in the dark for $6 \mathrm{~min}$, the solution was measured for absorbance at $735 \mathrm{~nm}$ in a UV-2600 spectrophotometer. The sample $(100 \mu \mathrm{L})$ was diluted with $95 \%$ ethanol $(v / v)$ to give $20 \%-80 \%$ inhibition of blank absorbance. Vitamin C (Vc) was used as a positive control. The capability to scavenge the ABTS radicals was calculated based on the following equation:

$$
I \%=[1-A s / A c] \times 100 \%
$$

where the $A c$ is the absorbance of the ABTS solution without sample $(100 \mu \mathrm{L}$ distilled water + $1.9 \mathrm{~mL}$ ABTS $)$ and $A s$ is the absorbance of the test sample mixed with ABTS solution $(100 \mu \mathrm{L}$ sample + $1.9 \mathrm{~mL}$ ABTS).

\subsubsection{Superoxide Anion Free Radical Scavenging Activity}

The superoxide radical scavenging activity of the samples was assessed using the NADH-PMS-NBT (Nicotinamide Adenine Dinucleotide-Phenazine Methyl Sulfate-Nitrotetrazolium Blue Chloride) method described in the literature with some modifications [47]. Different concentrations of samples were prepared by dissolving samples in Tris- $\mathrm{HCl}$ buffer solution $\left(\mathrm{pH} 8.0,0.05 \mathrm{mmol} \cdot \mathrm{L}^{-1}\right)$. The sample solutions were prepared by mixing with $0.5 \mathrm{~mL}$ nitroblue tetrazolium solution (NBT, $0.3 \mathrm{mmol} \cdot \mathrm{L}^{-1}$ ), $0.5 \mathrm{~mL}$ phenazine methyl sulfate solution $\left(0.06 \mathrm{mmol} \cdot \mathrm{L}^{-1}\right)$, and $0.5 \mathrm{~mL}$ of NADH solution $\left(0.468 \mathrm{mmol} \cdot \mathrm{L}^{-1}\right)$, respectively. The reaction mixture was placed at room temperature in the dark for $5 \mathrm{~min}$. The absorbance of the reaction mixtures was recorded at $560 \mathrm{~nm}$ with a UV-2600 spectrophotometer. The superoxide scavenging activity was expressed as percentage of inhibition. Results were calculated using the following formula:

$$
I \%=[1-A s / A c] \times 100 \%
$$

Ac was the absorbance of the blank without sample, while As was the absorbance of the sample.

\subsubsection{DPPH Radical Scavenging Activity Assay}

The DPPH free radical scavenging activity of the flavonoid-rich extracts was determined according to a previously reported method with some modifications [48]. Two milliliters of the total flavonoid solutions, at different concentrations, were mixed with $2.0 \mathrm{~mL}$ of freshly-prepared DPPH solution $\left(0.04 \mathrm{mg} \cdot \mathrm{mL}^{-1}\right.$ in $95 \%$ ethanol). After being thoroughly shaken and placed in the dark for $20 \mathrm{~min}$, the mixture was transferred to a centrifuge tube and then centrifuged at $3500 \mathrm{rpm}$ at $25^{\circ} \mathrm{C}$ for $20 \mathrm{~min}$. The supernatant was decanted, and the absorbance was measured at $517 \mathrm{~nm}$ against a blank using a UV-2600 spectrophotometer. Vitamin C was used as a reference compound in the same concentration range as the test compounds. A control solution was prepared in the same manner as the assay mixture 
without the tested compound. The capability of scavenging DPPH radicals as a percentage of DPPH remaining in the resulting solution was determined using the following equation:

$$
I \%=[1-(A i-A j) / A c] \times 100 \%
$$

where the $A c$ is the absorbance of the DPPH solution without sample $(2.0 \mathrm{~mL} 95 \%$ ethanol $+2.0 \mathrm{~mL}$ $\mathrm{DPPH}) ; A i$ is the absorbance of the test sample mixed with DPPH solution $(2.0 \mathrm{~mL}$ sample $+2.0 \mathrm{~mL}$ $\mathrm{DPPH})$ and $A j$ is the absorbance of the test sample $(2.0 \mathrm{~mL}$ sample $+2.0 \mathrm{~mL} 95 \%$ ethanol $)$.

\subsubsection{Hydroxyl Radical Scavenging Activity}

The Hydroxyl radical scavenging activity was performed using the method [49] with some minor changes. All solutions were freshly prepared. Two milliliters of various concentrations of sample were mixed with $2 \mathrm{~mL}$ of $\mathrm{FeSO}_{4}\left(6 \mathrm{mmol} \cdot \mathrm{L}^{-1}\right)$ and $2 \mathrm{~mL}$ of $\mathrm{H}_{2} \mathrm{O}_{2}\left(6 \mathrm{mmol} \cdot \mathrm{L}^{-1}\right)$. After being shaken, the mixture was placed at room temperature for $10 \mathrm{~min}$, and followed by the addition of $2 \mathrm{~mL}$ salicylic acid $\left(6 \mathrm{mmol} \cdot \mathrm{L}^{-1}\right)$. The mixture was shaken and incubated at room temperature in the dark for $30 \mathrm{~min}$. The absorbance of the reaction mixture was measured at $510 \mathrm{~nm}$ using a UV-2600 spectrophotometer. Extra pure water was used as a control solution, and Vc was used as reference. The ability to scavenge hydroxyl radicals was calculated using the following equation:

$$
I \%=[1-A s / A c] \times 100 \%
$$

where the $A c$ is the absorbance of solution without sample and $A s$ is the absorbance of the test sample.

\subsection{Isolation and Purification of Bioactive Compounds}

The 50\% ethanol and $60 \%$ ethanol fractions were further purified because of the higher content of total flavonoids and the strong antioxidant activities. Fifteen grams of $50 \%$ ethanol and $60 \%$ ethanol fractions of mixed powder was fractionated by normal-phase silica gel column chromatography and eluted with $\mathrm{CHCl}_{3} / \mathrm{MeOH}$ using a gradient solvent system $\left(\mathrm{CHCl}_{3} / \mathrm{MeOH}(9: 1,7: 1,5: 1,4: 1,1: 2, v / v)\right)$ to obtain eight fractions (Fr. 1-8).

Fr. 3 (1800 mg) was subjected to column chromatography over silica gel using a stepwise gradient elution of petroleum ether/ethyl acetate $(8: 1-1: 3, v / v)$ to get five subfractions (Subfr. 3.1-3.5). Subfr. 3.4 (300 mg) was separated by semi-preparative HPLC (ODS, $\mathrm{MeOH} / \mathrm{H}_{2} \mathrm{O}(60: 40, v / v)$ ) to obtain compound $1(28.0 \mathrm{mg})$.

Fr. 5 (1500 mg) was chromatographed using silica gel column chromatography to get five subfractions (Subfr. 5.1-5.5) using petroleum ether/acetone (1:3, v/v). Subfraction 5.4 (350 mg) was purified using a Toyperl $\mathrm{HW}-40 \mathrm{C}$ column with $\mathrm{CHCl}_{3} / \mathrm{MeOH}(2: 1, v / v)$ eluent to give compound 2 (35.4 mg).

Compound 3 (22.3 mg) was obtained by HPLC (ODS-A; $\mathrm{MeCN} / \mathrm{H}_{2} \mathrm{O}$ 3:7 $(v / v), 3.0 \mathrm{~mL} \cdot \mathrm{min}^{-1}$ ) from Fr. 6 (800 mg).

Fr. 7 (980 mg) was separated using semi-preparative HPLC (ODS, $\left.\mathrm{MeOH} / \mathrm{H}_{2} \mathrm{O}(45: 55, v / v)\right)$ to afford six subfractions (Subfr. 7.1-7.6). Subfraction 7.3 was then purified using HPLC (ODS-A, $\left.\mathrm{MeOH} / \mathrm{H}_{2} \mathrm{O}(4: 6, v / v), 3.0 \mathrm{~mL} \cdot \mathrm{min}^{-1}\right)$ to obtain compounds $4(35.6 \mathrm{mg})$ and $5(27.8 \mathrm{mg})$.

\subsection{Identification of the Isolated Compounds}

The chemical structures of the isolated compounds from the fractions with antioxidant activity were identified using Electrospray Ionization Mass Spectrometry (ESI-MS), ${ }^{1} \mathrm{H}$ Nuclear Magnetic Resonance Spectroscopy $\left({ }^{1} \mathrm{H}-\mathrm{NMR}\right)$, and ${ }^{13} \mathrm{C}$ Nuclear Magnetic Resonance Spectroscopy $\left({ }^{13} \mathrm{C}-\mathrm{NMR}\right)$ spectra with methanol or dimethyl sulfoxide (DMSO) used as solvent, and tetramethylsilane (TMS) used as internal standard. 


\subsection{Flavonoids Compounds Analysis by HPLC}

The dried and powered P. ostii flower was extracted twice with $75 \%$ ethanol $(v / v)$ at room temperature. The resulting extract was prepared as a solution in methanol, and the flavonoid-rich extracts and the isolated flavonoid compounds were also dissolved in methanol. All the samples were filtered through a $0.45 \mu \mathrm{m}$ filter, and then were injected into a Agilent 1100 HPLC system. The samples were eluted by using a Zorbax SB C18 column $(4.6 \times 250 \mathrm{~mm}, 5 \mu \mathrm{m})$ and detected at $360 \mathrm{~nm}$. The column temperature was set at $30^{\circ} \mathrm{C}$. The gradient elution was set as follows: Eluent A was $0.5 \%$ acetic acid, and eluent B was acetonitrile. Gradient, $0.0 \mathrm{~min}(40 \% \mathrm{~A}$ and $60 \% \mathrm{~B})-7 \mathrm{~min}$, (50\% A and 50\% B)-15 min (60\% A and 40\% B). The flow rate was kept constant at $1 \mathrm{~mL} / \mathrm{min}$, and the injection volume was $10 \mu \mathrm{L}$ for each run, which was performed in triplicate. The purity values of the isolated flavonoids were calculated using the area normalization method.

Flavonoids were identified by comparing their retention times with those of pure standards and by spiking the samples with standard solutions. Calibration curves were performed by injecting the standards three times at five different concentrations. Results were acquired, processed using the Agilent G2170BA software, and expressed as $\mathrm{mg} \cdot \mathrm{g}^{-1}$ sample of dry weight.

\subsection{Data Analysis}

All experiments were carried out in triplicate $(n=3)$. The results were analyzed and expressed as mean \pm standard deviation (SD). Statistical analysis was done using one-way analysis of variance.

\section{Conclusions}

In the Henan, Shandong, Anhui, Sichuan, and Gansu provinces, China, the flower of P. ostii is usually used for eating and drinking, and also for aromatherapy in order to purify and harmonize the body and soul [12]. This present study focused on the antioxidant activity and the chemical composition of the flavonoid-rich extracts from the flower of $P$. ostii. The results showed that $50 \%$ and $60 \%$ ethanol elutions, which had high contents of total flavonoids, from the polyamide resin column of this plant, showed a high potential for antioxidant activities. Additionally, the antioxidant activities were well correlated with the contents of the flavonoids. An investigation on the chemical constituents was carried out. Five flavonoid compounds, dihydrokaempferol, apigenin-7-O- $\beta$-D-glucoside, apigenin-7-O- $\beta$-D-neohesperidoside, kaempferol-3-O- $\beta$-D-glucopyranosyl-7-O- $\beta$-D-glucopyranoside, and kaempferol-7-O- $\beta$-D-glucopyranoside, were isolated and identified from the flavonoid-rich extracts. All the isolated flavonoids possessed significant ABTS, $\mathrm{O}^{2-}, \mathrm{DPPH}$ and $\bullet \mathrm{OH}$ radical scavenging activities. HPLC analysis showed that the main flavonoid components in the flavonoid-rich extracts and in the flower of $P$. ostii are very high, which perhaps contribute greatly to the antioxidant activity of this flower. Flavonoids are implicated in the maintenance of health because of their antioxidant properties and other bioactivities [50,51]. Radical scavenging activities are very important due to the deleterious role of free radicals in foods and biological systems. Excessive formation of free radicals accelerates the oxidation of lipids in foods and decreases food quality and consumer acceptance [52]. Our results indicated that the extract from the flower of $P$. ostii could be a natural antioxidant source, and might have potential applications in food and medical industries because of the higher levels of flavonoid constituents and good bioactivities. Flavonoids are widely distributed in genus Paeonia, especially in the flowers of the plants $[15,16]$. Therefore, in addition to the ornamental value, the flower of the genus Paeonia can also be used as the source of flavonoids, and used in the food and drug fields.

Acknowledgments: This work was financially supported by the National Natural Science Foundation of China (Nos. U1604192 and U1404831), funds from the High-Tech R\&D Program Grant from the Henan government of the People's Republic of China (Nos. 152102110079, 162102310202, and 16A210019), funds from the High-Tech R\&D Program Grant from Luoyang City of the People's Republic of China (Nos. 1301052A and 1401074A), and funds for the Student Research Training Plan (SRTP) from the Henan University of Science and Technology (2016057) and 
the Project of National College Students' Innovative and Entrepreneurial Training Plan of the People's Republic of China (201610464033).

Author Contributions: Pu Liu and Ruixue Deng conceptualized the project, and Ruixue Deng led the project. Huifang Zhang, Xiaofang Li, Ke Wu, Mengke Wang, Pu Liu, Xinsheng Wang, and Ruixue Deng performed the experiments. Pu Liu and Ruixue Deng were involved in the writing of the manuscript. We thank the National Natural Science Foundation of China for their financial support of this research.

Conflicts of Interest: The authors declare no conflicts of interest.

\section{References}

1. Zhong, J.Q.; Li, B.; Jia, Q.; Li, Y.M.; Zhu, W.L.; Chen, K.X. Advances in the structure-activity relationship study of natural flavonoids and its derivatives. Acta Pharm. Sin. 2011, 46, 622-630.

2. Yang, B.; Kotani, A.; Arai, K.; Kusu, F. Estimation of the antioxidant activities of flavonoids from their oxidation potentials. Anal. Sci. 2001, 17, 599-604. [CrossRef] [PubMed]

3. Hollman, P.C.; Katan, M.B. Dietary flavonoids: Intake, health effects and bioavailability. Food Chem. Toxicol. 1999, 37, 937-942. [CrossRef]

4. Ameha, S.; Kaleab, A.; Fathy, K.E.F. Structure-radical scavenging activity relationships of flavonoids. Phytochemistry 2006, 67, 2058-2070.

5. Bandyopadhyay, U.; Das, D.; Banerjee, R.K. Reactive oxygen species: Oxidative damage and pathogenesis. Curr. Sci. 1999, 77, 659-666.

6. Finkel, T. Radical medicine: Treating ageing to cure disease. Nat. Rev. Mol. Cell Biol. 2005, 6, 971-976. [CrossRef] [PubMed]

7. Finkel, T.; Holbrook, N.J. Oxidants, oxidative stress and the biology of ageing. Nature 2000, 408, $239-247$. [CrossRef] [PubMed]

8. Cotelle, N. Role of flavonoids in oxidative stress. Curr. Top. Med. Chem. 2001, 1, 569-590. [CrossRef] [PubMed]

9. Kaur, C.; Kapoor, H. Antioxidants in fruits and vegetables-the millennium's health. Int. J. Food Sci. Technol. 2001, 36, 703-725. [CrossRef]

10. Miller, A.L. Antioxidant flavonoids: Structure, function and clinical usage. Altern. Med. Rev. 1996, 1, $103-111$.

11. Pietta, P. Flavonoids as antioxidants. J. Nat. Prod. 2000, 63, 1035-1042. [CrossRef] [PubMed]

12. Li, J.J. Chinese Tree and Herbaceous Peonies; China Forestry Publishing House: Beijing, China, 1999; pp. 1-200.

13. Zhang, C.; Wang, W.N.; Wang, Y.J.; Gao, S.L.; Du, D.N.; Fu, J.X.; Dong, L. Anthocyanin biosynthesis and accumulation in developing flowers of tree peony (Paeonia suffruticosa) 'Luoyang Hong'. Postharvest Biol. Technol. 2014, 97, 11-22. [CrossRef]

14. Fu, L. Study on the Components and Antioxidant Capacity of the Peony Flower Pigment of P. ostii. Master's Thesis, North West Agriculture and Forestry University, Xianyang, China, 2011.

15. Wu, S.H.; Wu, D.G.; Chen, Y.W. Chemical Constituents and Bioactivities of Plants from the Genus Paeonia. Chem. Biodivers. 2010, 7, 90-104. [CrossRef] [PubMed]

16. He, C.N.; Peng, Y.; Zhang, Y.C.; Xu, L.J.; Gu, J.; Xiao, P.G. Phytochemical and Biological Studies of Paeoniaceae. Chem. Biodivers. 2010, 7, 805-838. [CrossRef] [PubMed]

17. Zeng, Y.W.; Deng, M.C.; Lv, Z.C.; Peng, Y.H. Evaluation of antioxidant activities of extracts from 19 Chinese edible flowers. SpringerPlus 2014, 3, 315. [CrossRef] [PubMed]

18. Wang, L.S.; Hashimoto, F.; Shiraishi, A.; Aoki, N. Phenetics in Tree Peony Species from China by Flower Pigment Cluster Analysis. J. Plant Res. 2001, 114, 213-221. [CrossRef]

19. Wang, L.S.; Hashimoto, F.; Shiraishi, A.; Aoki, N.; Li, J.J.; Sakata, Y. Chemical taxonomy of the Xibei tree peony from China by floral pigmentation. J. Plant Res. 2004, 117, 47-55. [PubMed]

20. Léonce, D. Sur la séparation du paeonoside et du malvoside au moyen de la chromatographie sur papier et sur couche mince de cellulose. J. Chromatogr. A 1968, 34, 425-427.

21. Wang, X.; Cheng, C.G.; Sun, Q.L.; Li, F.W.; Liu, J.H.; Zheng, C.C. Isolation and purification of four flavonoid constituents from the flowers of Paeonia suffruticosa by high-speed counter-current chromatography. J. Chromatogr. A 2005, 1075, 127-131. [CrossRef] [PubMed]

22. Hsu, F.L.; Lai, C.W.; Cheng, J.T. Antihyperglycemic effects of paeoniflorin and 8-debenzoylpaeoniflorin, glucosides from the root of Paeonia lactiflora. Planta Medica 1997, 63, 323-325. [CrossRef] [PubMed] 
23. Harborne, J.B. Comparative biochemistry of flavonoids-I: Distribution of chalcone and aurone pigments in plants. Phytochemistry 1966, 5, 111-115. [CrossRef]

24. Hosoki, T.; Hamada, M.; Kando, T.; Moriwaki, R.; Inaba, K. Comparative study of anthocyanin in tree peony flowers. J. Jpn. Soc. Hortic. Sci. 1991, 60, 395-403. [CrossRef]

25. Deng, R.X.; Liu, Z.; Qin, L.L.; Wang, L.; Liu, X.Q.; Liu, P. Optimization of Supercritical $\mathrm{CO}_{2}$ Extraction and Analysis of Chemical Composition of peony seed oil. Food Sci. 2010, 31, 142-145.

26. Liu, P.; Xu, Y.F.; Liu, Y.Q.; Hou, X.W.; Dong, J.Q.; Deng, R.X. Optimization of Ultrasonic-assisted Aqueous Extraction of peony seed oil. Sci. Technol. Cereals Oils Foods 2015, 23, $29-33$.

27. Liu, P.; Li, X.F.; Niu, Y.Q.; Deng, R.X.; Dong, J.Q.; Yin, W.P. Optimization extraction technology of oligostilbenes from seed cake of Peony for oil and its bioactivities. J. Chin. Cereal Oil Assoc. 2016, 31, 79-85.

28. Tian, G.L.; Zhao, G.L. Food of Peony Flowers's Exploitation and Development Prospects. Food Res. Dev. 2010, 31, 187-190.

29. Li, A.F.; Sun, A.L.; Liu, R.M.; Zhang, Y.Q.; Cui, J.C. An efficient preparative procedure for main flavonoids from the peel of Trichosanthes kirilowii Maxim. Using polyamide resin followed by semi-preparative high performance liquid chromatography. J. Chromatogr. B 2014, 965, 150-157. [CrossRef] [PubMed]

30. Zhang, J.; Hayat, K.; Zhang, X.; Tong, J.; Xia, S. Separation and purification of flavonoid from Ginkgo extract by polyamide resin. Sep. Sci. Technol. 2010, 45, 2413-2419. [CrossRef]

31. He, J.; Feng, Y.; Ouyang, H.Z.; Yu, B.; Chang, Y.X.; Pan, G.X.; Dong, G.Y.; Wang, T.; Gao, X.M. A sensitive LC-MS/MS method for simultaneous determination of six flavonoids in rat plasma: Application to a pharmacokinetic study of total flavonoids from mulberry leaves. J. Pharm. Biomed. Anal. 2013, 84, 189-195. [CrossRef] [PubMed]

32. Floegel, A.; Kim, D.O.; Chung, S.J.; Koo, S.I.; Chun, O.K. Comparison of ABTS/DPPH assays to measure antioxidant capacity in popular antioxidant-rich US foods. J. Food Compos. Anal. 2011, 24, 1043-1048. [CrossRef]

33. Fan, J.L.; Zhu, W.X.; Kang, H.B.; Ma, H.L.; Tao, G.J. Flavonoid constituents and antioxidant capacity in flowers of different Zhongyuan tree penoy cultivars. J. Funct. Foods 2012, 4, 147-157. [CrossRef]

34. Wang, X.; Shi, X.G.; Zheng, C.C.; Liu, J.H. Effect of extract from Peony flowers on removal of reactive oxygen species and preventing DNA damage caused by hydroxyl radical. Food Ferment. Ind. 2004, 30, 54-58.

35. Zhu, S.Y. Optimised extraction and antioxidant of polyphenols from Peony flowers. Biotechnology 2014, 24, $78-82$.

36. Sanchez-Moreno, C. Methods used to evaluate the free radical scavenging activity in foods and biological systems. Food Sci. Technol. Int. 2002, 8, 121-137. [CrossRef]

37. Soares, J.R.; Dinis, T.C.P.; Cunha, A.P.; Almeida, L.M. Antioxidant activity of some extracts of Thymus zygis. Free Radic. Res. 1997, 26, 459-478.

38. Wu, P.P.; Ma, G.Z.; Li, N.H.; Deng, Q.; Yin, Y.Y.; Huang, R.Q. Investigation of in vitro and in vivo antioxidant activities of flavonoids rich extract from the berries of Rhodomyrtus tomentosa (Ait.) Hassk. Food Chem. 2015, 173, 194-202. [CrossRef] [PubMed]

39. Babu, B.H.; Shylesh, B.S.; Padikkala, J. Antioxidant and hepato protective effect of Alanthus icicifocus. Fitoterapia 2001, 72, 272-277. [CrossRef]

40. Li, Y.S.; Li, D.M.; Jiang, L.Y.; Liu, G.M. Study on Chemical Constituents of Pinus yunnanensis. Chin. J. Exp. Tradit. Med. Formulae 2012, 18, 119-120.

41. Tan, X.Q.; Guo, L.J.; Chen, H.S.; Wu, L.S.; Kong, F.F. Study on the Flavonoids constituents of Trchelospermum jasminoides. J. Chin. Med. Mater. 2010, 33, 58-60.

42. Li, Y.Q.; Lei, X.X.; Feng, Y.L.; Xu, Q.M.; Xu, L.Z.; Yang, S.L. Study on the Chemical Constituents of Terpinia arguta. Chin. Pharm. J. 2012, 47, 261-264.

43. Qu, Y.K.; Dou, D.Q.; Pei, Y.P.; Yoshikawa, M.; Matsuda, H.; Chen, Y.J. Chemical Constituents of Opuntia dillenii. J. China Pharm. Univ. 2005, 36, 213-215.

44. Yu, R.M.; Li, X.; Zhang, H.J.; Wu, L.J.; Zhu, T.R.; Li, W.; Liu, L.Y.; Zhang, G. Study on the Chemical Constituents of Oxytropis glabra DC. J. Integr. Plant 1992, 34, 369-377.

45. Wu, L.Q.; Zhu, W.X.; Yi, J.P.; Zhang, Y.X.; Zhong, L.J. Study on Determination of Classification and Extraction Technology of Red Pigment in Peony Flower. Trans. Chin. Soc. Agric. Mach. 2015, 36, 77-80. 
46. Lu, J.; Qin, P.Z.; Han, X.; Wang, Y.P.; Li, Z.H. Evaluation of antioxidant and antibacterial properties of extracts from Trollius chinensis Bunge. Eur. Food Res. Technol. 2015, 240, 301-310. [CrossRef]

47. Tai, Z.G.; Chen, A.Y.; Qin, B.D.; Cai, L.; Xu, Y.Q. Chemical constituents and antioxidant activity of the Musa basjoo flower. Eur. Food Res. Technol. 2014, 239, 501-508. [CrossRef]

48. Ammar, R.B.; Bhouri, W.; Sghaier, M.B.; Boubaker, J.; Skandrani, I.; Neffat, A.; Bouhlel, I.; Kilani, S.; Mariotte, A.M.; Leila, C.G.; et al. Antioxidant and free radical-scavenging properties of three flavonoids isolated from the leaves of Rhamnus alaternus L. (Rhamnaceae): A structure-activity relationship study. Food Chem. 2009, 116, 258-264. [CrossRef]

49. Fu, R.; Zhang, Y.T.; Guo, Y.R.; Liu, F.X.; Chen, F. Determination of phenolic contents and antioxidant activities of extracts of Jatropha curcas L. seed shell, a by-product, a new source of natural antioxidant. Ind. Crop. Prod. 2014, 58, 265-270. [CrossRef]

50. Ross, J.A.; Kasum, C.M. Dietary flavonoids: Bioavailability, metabolic effects, and safety. Annu. Rev. Nutr. 2002, 22, 19-34. [CrossRef] [PubMed]

51. Agatia, G.; Azzarellob, E.; Pollastrib, S.; Tattinic, M. Flavonoids as antioxidant in Plants: Location and functional significance. Plant Sci. 2012, 196, 67-76. [CrossRef] [PubMed]

52. Gülçin, İ.; Elias, R.; Gepdiremen, A.; Taoubi, K.; Köksal, E. Antioxidant secoiridoids from fringe tree (Chionanthus virginicus L.). Wood Sci. Technol. 2009, 43, 195-212. [CrossRef]

Sample Availability: Samples of the compounds 1-5 are available from the authors.

(C) 2016 by the authors; licensee MDPI, Basel, Switzerland. This article is an open access article distributed under the terms and conditions of the Creative Commons Attribution (CC-BY) license (http://creativecommons.org/licenses/by/4.0/). 